\title{
Liquid slosh control by implementing model-free PID controller with derivative filter based on PSO
}

\author{
Mohd Zaidi Mohd Tumari ${ }^{1}$, Amar Faiz Zainal Abidin ${ }^{2}$, A Shamsul Rahimi A Subki ${ }^{3}$, \\ Ab Wafi Ab Aziz ${ }^{4}$, Muhammad Salihin Saealal ${ }^{5}$, Mohd Ashraf Ahmad ${ }^{6}$ \\ $1,2,3,4,5$ Center for Robotics and Industrial Automation, Faculty of Electrical \& Electronics Engineering Technology, \\ Universiti Teknikal Malaysia Melaka, Malaysia \\ ${ }^{6}$ Faculty of Electrical and Electronics Engineering Technology, Universiti Malaysia Pahang, Malaysia
}

\begin{abstract}
Article Info
Article history:

Received Sep 9, 2019

Revised Nov 11, 2019

Accepted Nov 25, 2019

\section{Keywords:}

Liquid slosh control

Model-free controller

PID controller

PSO

Sum squared error

ABSTRACT

Conventionally, the control of liquid slosh system is done based on modelbased techniques that challenging to implement practically because of the chaotic motion of fluid in the container. The aim of this article is to develop the tuning technique for model-free PID with derivative filter (PIDF) parameters for liquid slosh suppression system based on particle swarm optimization (PSO). PSO algorithm is responsible to find the optimal values for PIDF parameters based on fitness functions which are Sum Squared Error (SSE) and Sum Absolute Error (SAE) of the cart position and liquid slosh angle response. The modelling of liquid slosh in lateral movement is considered to justify the design of control scheme. The PSO tuning method is compared by heuristic tuning method in order to show the effectiveness of the proposed tuning approach. The performance evaluations of the proposed tuning method are based on the ability of the tank to follow the input in horizontal motion and liquid slosh level reduction in time domain. Based on the simulation results, the suggested tuning method is capable to reduce the liquid slosh level in the same time produces fast input tracking of the tank without precisely model the chaotic motion of the fluid.
\end{abstract}

Copyright () 2020 Institute of Advanced Engineering and Science. All rights reserved.

\section{Corresponding Author:}

Mohd Zaidi Bin Mohd Tumari,

Center for Robotics and Industrial Automation,

Faculty of Electrical \& Electronics Engineering Technology,

Universiti Teknikal Malaysia Melaka,

Hang Tuah Jaya, 76100 Durian Tunggal, Melaka, Malaysia.

Email: mohdzaidi.tumari@utem.edu.my

\section{INTRODUCTION}

The movement of the container system which contains liquid inside it usually faced a problem due to motion of the free liquid surface as known as slosh. The main problem of liquid slosh is it produces an additional moments and forces which can disturb the performance of the system. Hence, liquid slosh suppression is essential to solve the problems in numerous areas. For instance, the dynamic behavior of the ship carried a partly liquid filled tank onboard, is always disturbed because of additional forces and moments produced by a liquid slosh [1]. Another example, the pouring work in metal industries usually done by human operator. As we know, human tend to do an error because of many factors such as tiredness and carelessness. Consequently, human can cause sloshing and the molten metal will spill out from the ladle [2]. Moreover, the dynamics of the moving liquid cargo also can be troubled by the liquid slosh forces and moments acted in vertical and horizontal directions [3]. Thus, it is vital to suppress this liquid slosh problem during the movement of the container.

The goal of this study is to design the controller for the liquid slosh suppression HIL system so the tank can follow the prescribed location precisely in the same time, minimize the slosh angle. In recent years, 
several studies have focused on the liquid slosh control. Due to constraints of liquid slosh measurement, several passive approaches are executed to control the liquid slosh. For instance, absorbers and baffles are used as a passive elements to reduce the slosh energy in the container [4-5]. The drawbacks of these approaches to the system are heavy, bulky, require much time to construct and complex. Several attempts have been made to suppress the slosh of the liquid in the container by using feed-forward controller. For instance, minimum time feedforward control [6], filtering techniques [7], hybrid command smoothing and input shaping [8] and input shaping technique [9, 10]. These methods are used by generating the prescribed motion without using any feedback sensors, which reduced the residual slosh of the liquid generated in the tank. Disappointingly, feed-forward controllers are very sensitive to external perturbation occurred in the system. As an alternative, closed-loop control or feed-back control, which is popular with its robustness to external perturbation, has been applied to reduce the slosh of the liquid. For example, Variable Gain Super-twisting Algorithm (VGSTA) [11], sliding mode control [12], PID control [13-15], $H_{\infty}$ control [16], active force control (AFC) [17] and single input fuzzy logic controller [18].

As we know, practically, the traditional control techniques which depends on precise modelling of the system as known as model-based control, are hard to implement in the liquid container system because of difficulties to model the dynamic motion of the liquid and turbulent behavior of liquid slosh in the container. So, the more attractive approach which the controller design is done without knowing the precise model of the system as known as model-free control, has a good potential to implement in liquid container system for reducing the slosh. One of the model-free controller is Proportional-integral-derivative (PID) controller. PID is well known with its reliability and robustness and it has been widely used on the numbers of applications such as in [19-21]. Despite PID controller is able to solve those system control problems, the tuning of PID parameters is very tedious task. So, it is important to decrease the tuning time for PID controller to take full benefits of it. Therefore, for the last few decades, the optimal tuning of PID parameters are done by implementing the optimization techniques that proven to reduce the time of PID tuning.

The main objective in this paper is to find the optimal value of PIDF controller parameters for the nonlinear liquid slosh model. PSO is chosen to tune 8 parameters; $K_{p}, K_{i}, K_{d}$ and $\mathrm{N}$ to the optimal values for two PIDF controllers of the liquid slosh system. A considered amount of literature has been published on PSO tune PID in a number of applications such as [22, 23]. Those studies have proved that PSO is a good choice to tune the PID controller in their application. A nonlinear liquid slosh model in [24] which consists of a small motor-driven liquid tank performing a rectilinear motion is considered. The PSO tuning method is compared by heuristic tuning method in order to show the effectiveness of the proposed tuning approach. Based on the simulation results, the suggested tuning method is capable to reduce the liquid slosh level in the same time produces fast input tracking of the tank without precisely model the chaotic motion of the fluid.

The paper is organized as follows: Section 2 described the research method which consist of modelling of liquid slosh, PIDF controller and PSO algorithm, Section 3 presents the simulation results and discussion and finally, Section 4 concludes this paper.

\section{RESEARCH METHOD}

\subsection{Modelling of Liquid Slosh}

Figure 1 shows the modelling of liquid slosh that perform a movement in horizontal axis as a basis for simulation works in developing the tuning method for PIDF controller. The spring-mass-damper and a pendulum basically used to model the liquid slosh as a physical interpretation of fluid surface then created a slosh. The liquid slosh is modelled by a simple pendulum system performing the horizontal motion with a length, $l$ and slosh mass, $m$. The slosh angle, $\theta$ is indicated by the pendulum angle as shown in Figure 2 .

By referring to Figure 2,

$$
\begin{aligned}
& Y=l \sin \theta+y \\
& Z=l-l \cos \theta
\end{aligned}
$$

The kinetic energy is defined as

$$
T=\frac{1}{2} M(\dot{y})^{2}+\frac{1}{2} m(\dot{Y})^{2}+\frac{1}{2} m(\dot{Z})^{2}
$$

The potential energy is formulated as

$$
V=-m g l \cos \theta
$$


The Lagrangian of the system is the difference of kinetic energy and potential energy,

$$
L=T-V
$$
is given by

Then, the Euler-Lagrange equations in $y$ and $\theta$, which produce dynamic equations of the system,

$$
\begin{aligned}
& M \ddot{y}+m l \cos \theta \ddot{\theta}-m l^{2} \sin \theta=u \\
& m l \cos \theta \ddot{y}+m l^{2} \ddot{\theta}+d \dot{\theta}+m g l \sin \theta=0
\end{aligned}
$$

where $d, g, \theta, Z, Y, y, u, l, m$ and $M$ are damping coefficient, gravity, pendulum angle (slosh angle), displacement of $m$ in the vertical direction, displacement of $m$ in the horizontal direction, displacement of rigid tank, force applied for translational motion, hypotenuse length of the slosh (length of pendulum), mass of pendulum (slosh mass) and mass of the tank and liquid, respectively.

Table 1 shows the value of the liquid slosh system parameters used in this study. The quick-stop experiment as mentioned in [25] is used to find the system parameters by considering the liquid characteristics, tank dimension and the ratio of liquid fill.

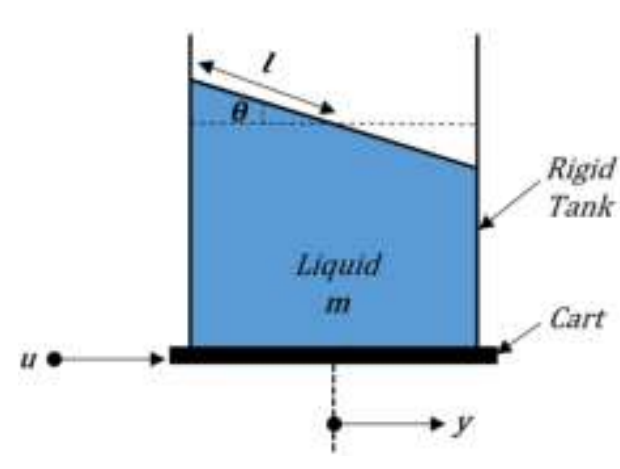

Figure 1. Liquid slosh model

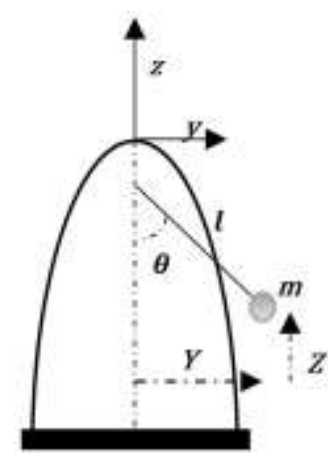

Figure 2. Liquid slosh modeled by simple pendulum

Table 1. Liquid Slosh Parameters [25]

\begin{tabular}{ccc}
\hline Parameter & Value & Unit \\
\hline$M$ & 6.0 & $\mathrm{~kg}$ \\
$m$ & 1.32 & $\mathrm{~kg}$ \\
$l$ & 0.052126 & $\mathrm{~m}$ \\
$g$ & 9.81 & $\mathrm{~ms}^{-2}$ \\
$d$ & $3.0490 \times 10^{-4}$ & $\mathrm{kgm}^{2} / \mathrm{s}$ \\
\hline
\end{tabular}

\subsection{PIDF Controller}

Figure 3 shows the block diagram of liquid slosh problem with two PIDF controllers, one for liquid slosh angle and another one for cart position control where $\theta(t), y(t), u(t), e(t)$ and $r(t)$ are slosh angle, cart position, control input, error and reference, respectively. $G$, is the motor-driven liquid tank system. The transfer function of PIDF controller, $K_{i}(s)(i=1,2)$ is defined as follow

$$
K_{i}(s)=P_{i}+I_{i} \frac{1}{s}+D_{i} \frac{N_{i}}{1+N_{i} \frac{1}{s}}
$$

where $P_{i}$ is the proportional gain, $I_{i}$ is the integral time, $D_{i}$ is the derivative time and $N_{i}$ is the filter coefficient.

The tuning method for PIDF parameters of liquid slosh control problem is done by minimizing the Sum Square Error (SSE) and Sum Absolute Error (SAE) based on the liquid slosh angle and cart position response. 


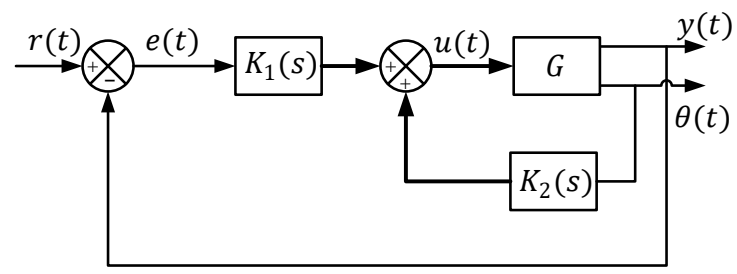

Figure 3. Block diagram of liquid slosh problem with PIDF controller

\subsection{Particle Swarm Optimization (PSO)}

PSO is a Swarm Intelligence (SI) algorithm motivated by the swarm of birds and fish schooling. In PSO algorithm, particles as known as agents will travel to it current best location and global best randomly by its current velocity that will be updated randomly later. Hence, to increase the efficiency of the swarm, the global communication between particles and real-number randomness is used in the algorithm.

Let $v_{i}$ and $x_{i}$ is the velocity vector and position vector for agent or particle $i$, respectively. 8 PIDF parameters to be adjusted, so the design parameter is stated in (9)

$$
x_{i}=\left[\begin{array}{llllllll}
P_{1} & I_{1} & D_{1} & N_{1} & P_{2} & I_{2} & D_{2} & N_{2}
\end{array}\right]
$$

Firstly, the particles velocity, $v_{i}$ and swarm particles, $x_{i}$ are set randomly using (10) and (11), respectively, where $u_{b}$ is an upper boundary and $l_{b}$ is a lower boundary set for the agents, while $r_{1}$ and $r_{2}$ is random real-number between [0 1].

$$
\begin{aligned}
& x_{i}=l_{b}+\left(u_{b}-l_{b}\right) \times r_{1} \\
& v_{i}=r_{2}
\end{aligned}
$$

For this simulation, an enhanced PSO algorithm using a priority-based fitness technique is recommended for PIDF tuning [26]. Sum squared error (SSE) of slosh angle, $\theta$ is set as uppermost primacy followed by sum absolute error (SAE) of $\theta$, sum square error (SSE) of cart position, $y$, sum absolute error (SAE) of $y$, overshoot (OS) of $y$ and settling time, Ts of $y$. The main concern is to get the smallest number of these fitness functions which are as shown in (12) to (17).

$$
\begin{aligned}
& f_{1}(x)=\text { Fitness }_{1}=S S E_{\theta}=\sum e_{\theta}^{2}(t) d t \\
& f_{2}(x)=\text { Fitness }_{2}=S A E_{\theta}=\sum\left|e_{\theta}\right|(t) d t \\
& f_{3}(x)=\text { Fitness }_{3}=S S E_{y}=\sum e_{y}^{2}(t) d t \\
& f_{4}(x)=\text { Fitness }_{4}=S A E_{y}=\sum\left|e_{y}\right|(t) d t \\
& f_{5}(x)=\text { Fitness }_{5}=\text { OS }_{y}=y_{\text {max }}-y_{\text {final }} \\
& f_{6}(x)=\text { Fitness }_{6}=\text { Settling Time }_{\text {Tim }}=\text { TS }_{y}
\end{aligned}
$$

The personal best agent is updated based on (18) as

$$
x_{t+1}^{*}=\left\{\begin{array}{c}
x_{t}^{i}, f_{1}\left(x_{t}^{i}\right)<f_{1}\left(X_{t}^{*}\right) A N D f_{2}\left(x_{t}^{i}\right)<f_{2}\left(X_{t}^{*}\right) A N D \ldots \\
\ldots f_{3}\left(x_{t}^{i}\right)<f_{3}\left(X_{t}^{*}\right) A N D f_{4}\left(x_{t}^{i}\right)<f_{4}\left(X_{t}^{*}\right) A N D \ldots \\
\ldots . f_{5}\left(x_{t}^{i}\right)<f_{5}\left(X_{t}^{*}\right) \text { AND } f_{6}\left(x_{t}^{i}\right)<f_{6}\left(X_{t}^{*}\right) \\
x_{t}^{*}, \text { otherwise }
\end{array}\right.
$$

The global best is updated by using in (19) 


$$
g_{t+1}^{*}=\left\{\begin{array}{c}
x_{t}^{i}, f_{1}\left(x_{t}^{i}\right)<f_{1}\left(g_{t}^{*}\right) A N D f_{2}\left(x_{t}^{i}\right)<f_{2}\left(g_{t}^{*}\right) A N D \ldots . \\
\ldots f_{3}\left(x_{t}^{i}\right)<f_{3}\left(g_{t}^{*}\right) A N D f_{4}\left(x_{t}^{i}\right)<f_{4}\left(g_{t}^{*}\right) A N D \ldots \\
\ldots . f_{5}\left(x_{t}^{i}\right)<f_{5}\left(g_{t}^{*}\right) \text { AND } f_{6}\left(x_{t}^{i}\right)<f_{6}\left(g_{t}^{*}\right) \\
g_{t}^{*}, \text { otherwise }
\end{array}\right.
$$

Then, the updated velocity for the particle is obtained by (20)

$$
v_{i}^{t+1}=w_{i} \times v_{i}+\alpha \times r_{3} \times\left(g^{*}-x_{i}^{t}\right)+\beta \times r_{4} \times\left(x^{*}-x_{i}^{t}\right)
$$

where, an inertia function, $w_{i}$ as (16) is used to update the velocity, $v_{i}^{t+1}$ in every new iteration $(t+1)$ per (22) [27], $r_{3}$ and $r_{4}$ is random real-number between [0 1], the parameters $\beta$ and $\alpha$ are the personal coefficient and social coefficient, respectively. Typically, these coefficients are constant and set to 2 .

$$
w_{i}=0.4+0.5 \times \frac{N_{i}-i}{N_{i}}
$$

The new position then is updated by

$$
x_{i}^{t+1}=x_{i}+v_{i}^{t+1}
$$

The simulation stopped after the maximum iteration is reached and the best PIDF parameters obtained by PSO algorithm is presented.

\section{RESULTS AND ANALYSIS}

The performance evaluations of the proposed tuning method are based on the ability of the cart to follow the input in horizontal motion and liquid slosh level reduction in time domain. The step input is set to 0.5 meter with zero initial conditions as stated in (23)

$$
r(t)=\left\{\begin{array}{cc}
0, & 0 \leq t \leq 0.5 \\
0.5 m, & 0.5<t \leq 20
\end{array}\right.
$$

The simulation works are done with MATLAB 2016, Microsoft Window 10, 8GB RAM and Intel Core i7-6700 Processor (3.41GHz). The liquid slosh model as stated in (6) and (7) are designed via Simulink.

The simulation is run for $20 \mathrm{~s}$ and the sampling time is fixed at $0.01 \mathrm{~s}$. The maximum iteration for this work is set at only 12 iterations. For inertia function, $w$, the initial value is set to 0.9 and decreased linearly to 0.4 by using (21). Only 2 particles or agents are used in this work that contribute to 24 number of evaluations. The upper and lower boundary is set initially as follow:

$$
\begin{aligned}
& \text { lower boundary }=l_{b}=\left[\begin{array}{llll}
0 & 0.00100 & 100 & 5020100
\end{array}\right] \\
& \text { upper boundary }=u_{b}=\left[\begin{array}{ll}
5 & 0.0051051206030120
\end{array}\right]
\end{aligned}
$$

The PSO tuning method is compared by manual heuristic tuning method in order to show the effectiveness of the proposed tuning approach and the results for optimal PIDF paratmeters for both methods is shown in Table 2.

Table 2. PIDF Parameters Obtained by PSO and Heuristic Tuning

\begin{tabular}{ccc}
\hline PIDF gain & PSO Tuning & Heuristic Tuning \\
\hline$P_{1}$ & 3.2769 & 20.0 \\
$I_{1}$ & 0.0015 & 0.1 \\
$D_{1}$ & 6.2659 & 10.0 \\
$N_{1}$ & 1.3856 & 10.0 \\
$P_{2}$ & 105.4218 & 110.0 \\
$I_{2}$ & 53.3039 & 60.0 \\
$D_{2}$ & 20.3509 & 30.0 \\
$N_{2}$ & 114.0931 & 120.0 \\
\hline
\end{tabular}


Figure 4 shows the simulation result on cart position response for both PIDF controller tuning method. It can be seen from the response in Figure 4 that, for PSO tuning, the cart is able to follow the prescribed input trajectory presicely without any steady state error and small overshoot about $3 \%$. The settling time recorded is $7.5 \mathrm{~s}$. On the other hand, for the heuristic tuning, the settling time is much longer about $10 \mathrm{~s}$ and the response produces huge overshoot about $20 \%$. In term of rise time, heuristic tuning produces faster rise time which is $1.5 \mathrm{~s}$ compared to PSO tuning which is $3 \mathrm{~s}$. What is interesting about the result in Figure 4 is PSO tuning produces much better performance compared to heuristic tuning in terms of time response specification.

Figure 5 presents the slosh angle response for both tuning method. As can be seen from Figure 5, by heuristic tuning, the maximum residual of liquid slosh is \pm 0.11 radian and settled within $9 \mathrm{~s}$. Interestingly, by PSO tuning, there is significant improvement for liquid slosh reduction where the maximum residual is decreased to \pm 0.025 radian and settled within 6 s. This result is supported with the slosh rate in Figure 6 where by using PSO tuning, the maximum slosh rate is \pm 0.25 radian/sec while by tuning heuristically, the maximum slosh rate is $\pm 2.3 \mathrm{radian} / \mathrm{sec}$. The result of the necessary control efforts is shown in Figure 7 . From the result we can see that the control signal overshoots when the desired stimulus is applied to the system. The maximum control input of heuristic tuning is bigger compared to PSO tuning. For heuristic tuning, the maximum control input is 60 Newton while for PSO tuning, the maximum control input is 5 Newton. In summary, these results show that the PSO tuning for PIDF parameters is surpassed the heuristic tuning in suppressing the liquid slosh in the same time, achieved the desired cart position. Table 3 summarizes the results obtained from the simulation analysis.

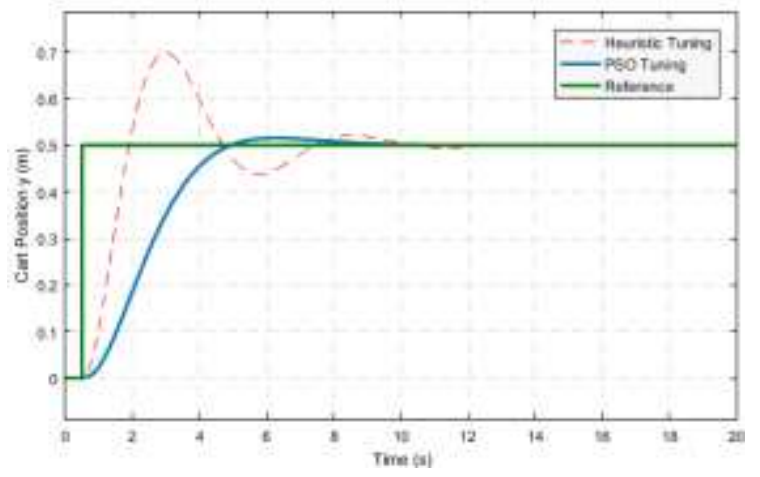

Figure 4. The response of cart position

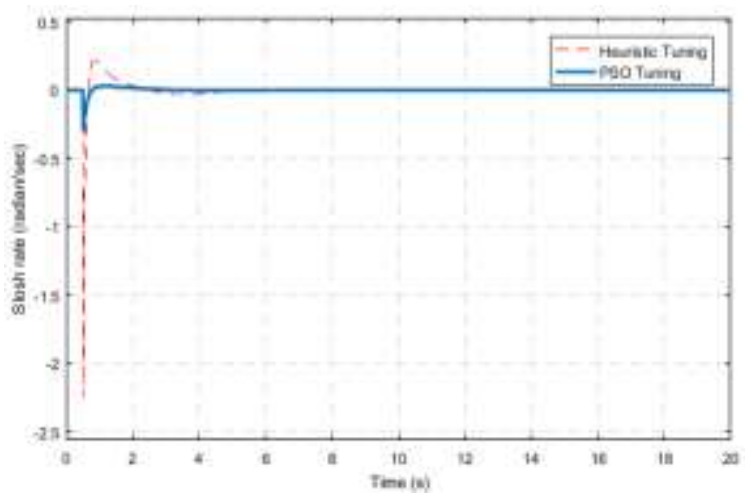

Figure 6. The response of slosh rate

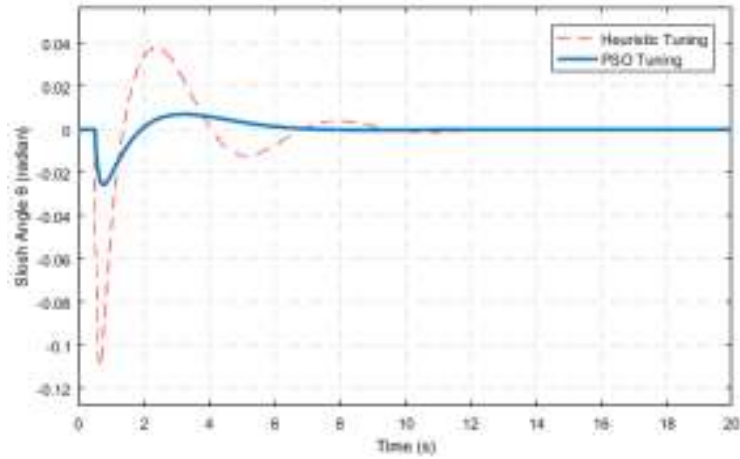

Figure 5. The response of slosh angle

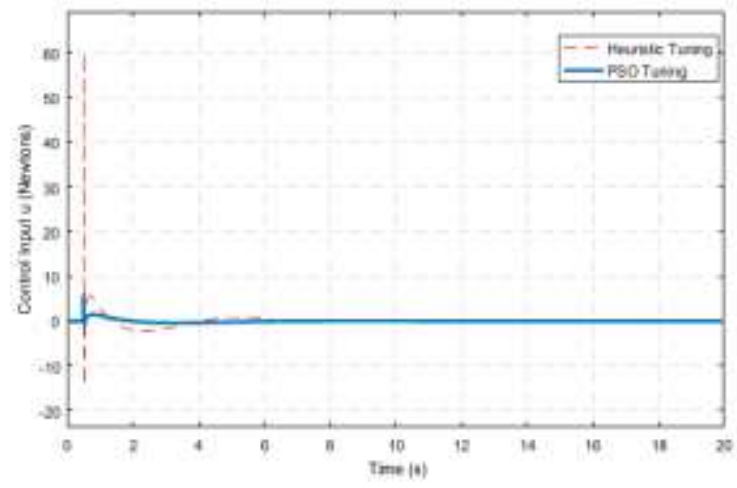

Figure 7. The response of control input

Table 3. The results of Liquid Slosh System

\begin{tabular}{cccccccc}
\hline $\begin{array}{c}\text { Method of } \\
\text { tuning }\end{array}$ & $\begin{array}{c}\text { Maximum } \\
\text { Slosh angle, } \\
\theta(\text { radian })\end{array}$ & $\begin{array}{c}\text { Rise Time, } \\
\operatorname{Tr}(\mathrm{s})\end{array}$ & $\begin{array}{c}\text { Maximum } \\
\text { Slosh rate } \\
(\mathrm{rad} / \mathrm{sec})\end{array}$ & $\begin{array}{c}\text { Steady State } \\
\text { error }\end{array}$ & $\begin{array}{c}\text { Control input } \\
\text { Overshoot } \\
(\mathrm{N})\end{array}$ & $\begin{array}{c}\text { Percentage } \\
\text { Overshoot, } \\
\% \text { OS }(\%)\end{array}$ & $\begin{array}{c}\text { Settling } \\
\text { Time, Ts }(\mathrm{s})\end{array}$ \\
\hline PSO & 0.025 & 3.0 & 0.25 & 0.0 & 5 & 3 & 7.5 \\
Heuristic & 0.11 & 1.5 & 2.3 & 0.0 & 60 & 20 & 10.0 \\
\hline
\end{tabular}




\section{CONCLUSION}

The aim of the present research was to develop the tuning method for PIDF controller for liquid slosh system by implementing the PSO algorithm. This study has shown that there is a significant improvement of PSO tuned PIDF controller if compared to tuning heuristically in terms of cart capability to follow the desired input and reduction of liquid slosh in the container. The results of this study indicate that the proposed tuning method for PIDF controller is a good choice to be apply in aforesaid sectors in order to solve the liquid slosh problem. The tuning method used for this study may be applied to other nonlinear applications elsewhere in the world. The main weakness of this study was just a few number of particles and iterations is applied for tuning process. This is because the highly nonlinear model of liquid slosh that contribute to error during simulation works. More research is required to determine the efficacy of PSO tuning especially in the high number of particles and iterations. Further works on experimentation of liquid slosh tank driven by motor by using model-free control approach is strongly recommended.

\section{ACKNOWLEDGEMENTS}

This work was financed by reseach grant FRGS/1/2017/ICT02/UMP/02/2 and PJP/2018/FTK(10B)/S01610 from Universiti Teknikal Malaysia Melaka.

\section{REFERENCES}

[1] P. Krata, "Linear Characteristics of the Sloshing Phenomenon for the Purpose of On-Board Ship's Stability Assessment," Journal of Theoretical and Applied Mechanics, vol. 47, no 2, pp. 307-320, 2009.

[2] K. Terashima and K. Yano, "Sloshing analysis and suppression control of tilting-type automatic pouring machine," Control Engineering Practice, vol. 9, pp. 607-620, 2001.

[3] T. Acarman and U. Ozguner, "Rollover prevention for heavy trucks using frequency shaped sliding mode control," International Journal of Vehicle Mechanics and Mobility, vol. 44, no. 10, 2006.

[4] B. U. Guzel, M. Gradinscak, S. E. Semercigil and O. F. Turan, "Control of Liquid Sloshing in Flexible Containers: Part 1. Added Mass," in 15th Australasian Fluid Mechanics Conference, Sydney, Australia, 13-17 December 2004.

[5] A. P March, M. Prakash, S. E. Semercigil and O. F. Turan, "A shallow-depth sloshing absorber for structural control," Journal of Fluids and Structures, vol. 26, pp. 780-792, 2010.

[6] A. Alsaibie and W. Singhose, "Experimental Testing of Liquid Slosh Suppression in a Suspended Container with Compound-Pendulum Dynamics, " in 9th Asian Control Conference (ASCC), Istanbul, 2013, pp. 1-6.

[7] A. Samba, Murthy, A. Kivila and W. Singhose, "Slosh Suppression of a Liquid in a Suspended Container using Robust Input Shaping," in 19th International Congress on Sound and Vibration, Vilnius, Lithuania, July 8-12. 2012. pp. 1-8.

[8] Q. Zang, J. Huang and Z. Liang, "Slosh Suppression for Infinite Modes in a Moving Liquid Container," IEEE/ASME Transactions on Mechatronics, vol. 20, no. 1, pp. 217-225, 2015.

[9] L. Moriello, L. Biagiotti, C. Melchiorri and A. Paoli, "Control of Liquid Handling Robotic Systems: a FeedForward Approach to Suppress Sloshing," in IEEE International Conference on Robotics and Automation (ICRA), Singapore, May 29-June 3, 2017, pp. 4286-4291.

[10] L. Consolini, A. Costalunga. A. Piazzi and M. Vezzosi, "Minimum-time feedforward control of an open liquid container," in IECON 2013 - 39th Annual Conference of the IEEE Industrial Electronics Society, Vienna, 2013, pp. 3592-3597.

[11] J. Mishra, P. and S. R. Kurode, "Robust Output-Feedback Control for Container-Slosh System using Variable Gain Super-Twisting Algorithm," in 13th IEEE Workshop on Variable Structure Systems, Nantes, France. June 29-July 2, 2014, pp. 1-6.

[12] S. Kurode, S. K. Spurgeon, B. Bandyopadhyay and P. S. Gandhi, "Sliding Mode Control for Slosh-Free Motion Using a Nonlinear Sliding Surface," IEEE/ASME Transactions on Mechatronics, vol. 18, no. 2, pp. 714-724, 2013.

[13] M. A. Ahmad, M. A. Rohani, R. M. T. Raja Ismail, M. F. Mat Jusof, M. H. Suid and A. N. K. Nasir, "A ModelFree PID Tuning to Slosh Control using Simultaneous Perturbation Stochastic Approximation," in IEEE International Conference on Control System, Computing and Engineering (ICCSCE), George Town, 2015, pp. 331 335.

[14] N. S. Abdul Shukor, M. A. Ahmad and M. Z. Mohd Tumari, "Data-driven PID Tuning based on Safe Experimentation Dynamics for Control of Liquid Slosh," in IEEE 8th Control and System Graduate Research Colloquium (ICSGRC), 4-5 August 2017, Shah Alam, Malaysia, pp. 62-66.

[15] B. Robu, L. Baudouin, C. Prieur and D. Arzelier, "Simultaneous H-infinity vibration control of liquid/plate system via reduced-order controller," IEEE Transactions on Control Systems Technology, Institute of Electrical and Electronics Engineers, vol. 20, no. 3, pp 700-711, 2012.

[16] N. M. Z. A. Mustapha, M. Z. Mohd Tumari, M. H. Suid, R. M. T. Raja Ismail and M. A. Ahmad. "Data-Driven PID Tuning for Liquid Slosh-Free Motion Using Memory-Based SPSA Algorithm," in Proceedings of the 10th National Technical Seminar on Underwater System Technology. Springer, Singapore. pp. 197-210. 2018.

[17] Purnomo, D. Setyo, A. R. Anom Besari and Z. Darojah, "Control of Liquid Sloshing Container using Active Force Control Method,” IOP Conf. Series: Materials Science and Engineering, vol. 190, pp. 1-8, 2017. 
[18] M. Z. Mohd Tumari, S. Saat, M. S. Johal, M. F. Bahari and M. A. Ahmad. "Single Input Fuzzy Logic Controller for Liquid Slosh Suppression," International Journal of Electrical Engineering and Applied Sciences (IJEEAS). Vol. 2 (1). pp. 45-52. 2019.

[19] Sarah N. Al-Bargothi, Ghazi M. Qaryouti, Qazem M. Jaber. "Speed control of DC motor using conventional and adaptive PID controllers, " Indonesian Journal of Electrical Engineering and Computer Science (IJEECS). Vol. 16 (3). pp. 1221-1228. 2019.

[20] Badriyah Ahmed Obaid, Ameer Lateef Saleh, Abbas Kareem Kadhim. "Resolving of optimal fractional PID controller for DC motor drive based on anti-windup by invasive weed optimization technique, " " Indonesian Journal of Electrical Engineering and Computer Science (IJEECS). Vol. 15 (1). pp. 95-103. 2019.

[21] M. Z. Mohd Tumari, L. Shabudin, M. A. Zawawi, L. H. Ahmad Shah, "Active sway control of a gantry crane using hybrid input shaping and PID control schemes, ” IOP Conference Series: Materials Science and Engineering, vol. 50, no. 1, pp. 1-11, 2013.

[22] A. Noordin, M. A. Mohd Basri, Z. Mohamed and A. F. Zainal Abidin, "Modelling and PSO Fine-tuned PID Control of Quadrotor UAV," International Journal on Advanced Science Engineering Information Technology, vol. 7, no. 4, pp. 1367-1373, 2017.

[23] M. Z. Mohd Tumari, A. F. Zainal Abidin, M. S. F. Hussin, A. M. Abd Kadir, M. S. Mohd Aras and M. A. Ahmad, "PSO Fine-Tuned Model-Free PID Controller with Derivative Filter for Depth Control of Hovering Autonomous Underwater Vehicle, “ Lecture Notes in Electrical Engineering (Springer). Vol. 538. pp. 3-13. 2019.

[24] H. N. Abramson, "Analytical representation of lateral sloshing by mechanical models," NASA, Washington, DC, NASA Rep. SP-106, pp. 199-224, 1996.

[25] K. Joshi, "Modelling and analysis of fluid slosh under translation and pitching excitation," M. S. Thesis, Indian Institute Technology, 2006, Bombay, India.

[26] H. I. Jaafar, Z. Mohamed, A. F. Zainal Abidin and Z. Ab Ghani, "PSO-Tuned PID controller for a Nonlinear Gantry Crane System," in 2012 IEEE International Conference on Control System, Computing and Engineering, 23-25 Nov 2012, Penang, Malaysia, pp. 515-519.

[27] A. Adam, A. F. Zainal Abidin, Z. Ibrahim, A. R. husain, Z. M. Yusof and I. Ibrahim, "A Particle Swarm Optimization Approach to Robotic Drill Route Optimization," in Fourth Asia Int. Conf. Math. Model. Computer Simulation, 26-28 May 2010, pp. 60-64.

\section{BIOGRAPHIES OF AUTHORS}
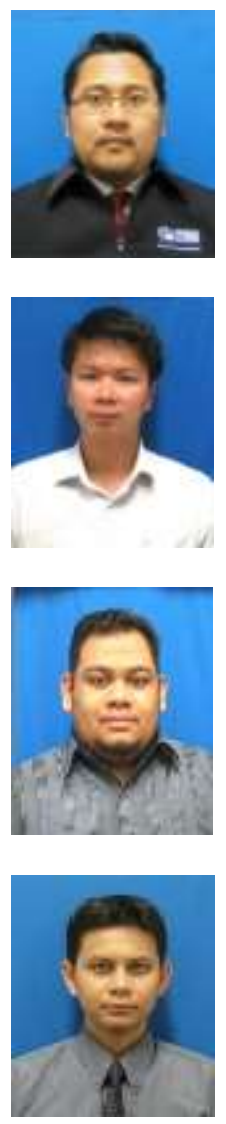

Mohd Zaidi Bin Mohd Tumari is a lecturer in Universiti Teknikal Malaysia Melaka. He has a Master of Electrical (Mechatronics and Automatic Control) Engineering in 2010 and Bachelor of Electrical Engineering (Mechatronic) in 2008 from Universiti Teknologi Malaysia. His research area includes swarm intelligence, computational intelligence and control system.

Amar Faiz Bin Zainal Abidin is a lecturer in Universiti Teknikal Malaysia Melaka. He has a Master of Electrical (Mechatronics and Automatic Control) Engineering from UTM and Bachelor of Electrical \& Electronics Engineering from University of Nottingham. His research area includes swarm intelligence, computational intelligence and computer vision.

A Shamsul Rahimi Bin A Subki is a lecturer in Universiti Teknikal Malaysia Melaka. He has a Master of Science (Microelectronics) from UKM and Bachelor of Engineering (Microelectronics Engineering) from UKM. His research area includes microelectronics, semiconductor and power electronics.

$\mathrm{Ab}$ Wafi Bin Ab Aziz is a lecturer in Universiti Teknikal Malaysia Melaka. He has a Master of Engineering (Electrical-Mechatronic and Automatic Control) from UTM and Bachelor of Engineering (Electrical \& Electronics) from UTP. His research area includes control \& instrumentation. 


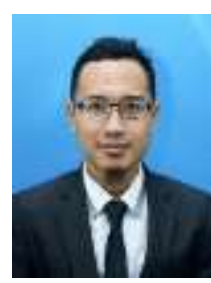

Muhammad Salihin Bin Saealal is a lecturer in Universiti Teknikal Malaysia Melaka. He has a Master of Electrical (Mechatronics and Automatic Control) Engineering and Bachelor of Electrical (Instrumentation Control) Engineering from UTM. His research area includes instrumentation, programming and control system.

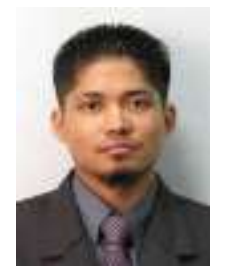

Dr. Mohd Ashraf Ahmad is a senior lecturer in Universiti Malaysia Pahang. He has a PhD in Informatics (Systems Science) from Kyoto University in 2015, Master of Electrical (Mechatronics and Automatic Control) Engineering in 2008 and Bachelor of Electrical (Mechatronic) Engineering in 2006 from UTM. His research area includes swarm intelligence, computational intelligence and control system. 